\title{
A percepção dos jovens e adultos sobre evasão escolar: uma visão merlopontiliano
}

Young and adults 'perception of school evasion: a merlopontilian view.

Percepción de jovenes y adultos de evasión escolar: una visión merlopontiliana.

Rita de Cássia Ferreira da Silva ${ }^{1}$, Rose Mary Costa Rosa Andrade Silva ${ }^{2}$, Eliane Ramos Pereira ${ }^{3}$, Mônica Moura da Silveira Lima ${ }^{4}$

Como citar esse artigo. da Silva, RCF; Silva, RMCRA; Pereira, ER; Lima, MMS. A percepção dos jovens e adultos sobre evasão escolar: uma visão merlopontiliano. Revista PróUniverSUS. 2020 Jan./Jun.; 11 (1): $170-172$

\section{Resumo}

Problema: O estresse vem fazendo parte do cotidiano das pessoas; considerado um problema de saúde pública. Vale ressaltar os fatores estressores, devido a traumas vividos como: violência, drogas, perda da família, depressão e outros. Nesse contexto, foi delimitado como objetivo geral: compreender a vivência do estudante do ensino da (EJA), envolvido pela evasão escolar, como objetivos específicos: identificar os fatores estressores e descrever a percepção desse público, diante dessa evasão escolar. Metodologia: trata-se de uma pesquisa descritiva de abordagem qualitativa com embargo na fenomenologia existencial de Merleau-Ponty uma vez que intenciona desvelar, compreender, e revelar uma situação existencial vivenciada pelo ser humano. O cenário será uma escola municipal de São Gonçalo/RJ, com foco no ensino fundamental I e II, em horário noturno, que utiliza a metodologia educacional voltada para a EJA. Os participantes serão alunos, considerados maiores e que desejarem participar de forma voluntária. Como instrumento de coleta de dados, será utilizada entrevista semiestruturada e acontecerá após aprovação pelo comitê de ética da UFF em concordância com as resoluções do Conselho Nacional de Saúde de $n^{\circ}$ 466/2012 e 510/2016. Como Perspectiva: será elaborado um material educativo, na forma de cartilha ilustrativa, que descreva a vivência dos alunos, no formato de história em quadrinhos. Conclusão: dessa maneira espera-se contribuir na redução da evasão escolar e melhorar

Palavras-chave: Jovens;Adultos, Estudantes, Evasão Escolar, Escola

\section{Abstract}

Problem: Stress has been part of everyday life; considered a public health problem. It is worth emphasizing the stressors, due to traumas experienced as: violence, drugs, family loss, depression and others. In this context, it was defined as a general objective: to understand the experience of the EJA student, involved in school evasion, as specific objectives: to identify the stressors and to describe the perception of this public, in the face of this school dropout. Methodology: it is a descriptive research of qualitative approach with embargo in the existential phenomenology of Merleau-Ponty since it intends to unveil, to understand, and to reveal an existential situation lived by the human being. The scenario will be a municipal school in São Gonçalo / RJ, focused on elementary education I and II, at night, which uses the educational methodology focused on the EJA. The participants will be students, considered to be larger and who wish to participate voluntarily. As a data collection instrument, a semi-structured interview will be used and will take place after approval by the UFF ethics committee in accordance with National Health Council resolutions n ${ }^{\circ} 466 / 2012$ and 510/2016. As a Perspective: an educational material, in the form of an illustrative primer, will be elaborated that describes the experience of the students, in the comic book format. Conclusion: this way we hope to contribute to reduce school dropout.

Keywords: Young;Adults, Students, Student Dropouts, School

\section{Resumen}

Problema: elestrésha sido parte de la vida cotidiana; Consideradoun problema de salud pública. Cabe destacar losfactoresestresantes, debido a traumas experimentados como: violencia, drogas, pérdida familiar, depresión y otros. En este contexto, se definió como unobjetivo general: comprenderla experiencia delestudiante de EJA, involucrado enlaevasión escolar, como objetivos específicos: identificar losfactores de estrés y describirlapercepción de este público, ante esta deserción escolar. Metodología: es una investigacióndescriptivadel enfoque cualitativocon embargo enlafenomenologíaexistencial de MerleauPonty, ya que pretende desvelar, comprender y revelar una situación existencial vivida por el ser humano. El escenario será una escuela municipal en São Gonçalo / RJ, enfocada enlaeducaciónelemental I y II, por lanoche, que utiliza lametodología educativa enfocada enla EJA. Los participantes seránestudiantes, considerados más grandes y que deseen participar voluntariamente. Como instrumento de recolección de datos, se utilizará una entrevista semiestructurada y se llevará a cabo después de laaprobación por parte del comité de ética de la UFF, de conformidadconlasresoluciones n. 466/2012 y 510/2016 delConsejo Nacional de Salud. Como Perspectiva: se elaborará un material educativo, en forma de un manual ilusevasión escolar. trativo, que describala experiencia de losestudiantes, en formato de cómic. Conclusión: de esta manera esperamos contribuir a reducirlaevasión escolar.

Palabras clave: Jóvene, Adultos, Estudiantes, Evasión Escolar, Escuela

1. Mestranda da Universidade Federal Fluminense, Niterói, RJ, Brasil. Email: rdecassiaferreira@hotmail.com ORCID· https://orcid org/0000-0002-8155-6910

2. Profa. Titular da Universidade Federal Fluminense, UFF. Niterói, RJ, Brasil. Email: roserosa.uff@gmail.com ORCID: https://orcid.org/0000-0002-6403-2349

3. Profa. Titular da Universidade Federal Fluminense, UFF. Universidade Federal Fluminense. Niterói, RJ, Brasil. Email: elianeramos.uff@gmail.com ORCID: https://orcid. org/0000-0002-6381-3979

4. Universidade Federal Fluminense. Niterói, RJ, Brasil. Email: monicam.silveira@gmail.com ORCID: https://orcid.org/0000-0003-3540-6679 


\section{Introdução}

A escola é uma instituição de formação essencial à vida dos sujeitos, no processo de construção dos saberes e seus valores, fomentada a partir de ações educativas, moldando o cidadão, onde crianças e jovens passam um tempo considerável de suas vidas ${ }^{1}$.

Sendo de forma significativa, a única instituição social, na qual toda a população infanto-juvenil, necessita vivenciar, conforme nos revela o Estatuto da Criança e do Adolescente no Cotidiano ${ }^{2}$, cabe à escola formar alunos com censo crítico, autônomo e reflexivo, isto é, pessoas conscientes de seus direitos e deveres, compreendendo assim a realidade, econômica, social e política do espaço geográfico em que vivem.

Mediante esta responsabilidade, professores e alunos são envolvidos por uma esfera de desafios, lembrando que os idosos passaram fazer parte da Educação Jovens e Adultos (EJA). Assim se faz necessário buscar ações e soluções para inclusão dos idosos diante dessa realidade.

A educação brasileira perpassa por problemas, a exemplo os fatores que promovem a evasão escolar. De forma que,a maioria desses alunos não concluem o período letivo por vários motivos. É necessário ter diretriz para a compreensão da dimensionalidade da evasão e do abandono escolar,diante da realidade brasileira $^{3}$.

O autor citado a cima relata causas que se apresentam como desagregadoras da educação, em todas as regiões do país,não se permitindo uma leitura precisa de "evasão e abandono escolar", uma vez que esta requer uma compreensão das relações entre os motivos de ingresso e a trajetória dos que permanecem,também dos desistentes e egressos desse público.

A literatura cita algumas indefinições como: Inep (1998) e Ideb (2012) que trazem à tona a falta de conceito claro para evasão e abandono escolar. E continua a dizer que: fatores internos e externos, como drogas, tempo na escola, sucessivas reprovações, falta de incentivo da família e da escola também contribuem para o insucesso escolar ${ }^{3}$.

Revela, a necessidade de trabalhar, excesso de conteúdo escolar, alcoolismo, localização da escola, vandalismo, falta de formação de valores e preparo para o mundo do trabalho, podem ser considerados decisivos no momento de ficar ou sair da escola.

Da mesma forma, abarca este contexto, de maneira bem especifica remete alguns estressores como: violência, drogas, perda da família, gravidez precoce, necessidade de trabalhar muito cedo, ansiedade, depressão, sobrecarga de trabalho, insônia e outros. ${ }^{4}$ São fatores que contribuem para o aumento da evasão escolar ${ }^{3}$.

Essa questão é considerada uma questão de saúde publica, denominado estresse, que podem ser desencadeados por traumas vividos ${ }^{4}$. A evasão escolar é preocupante, principalmente quando há abandono por tempo indeterminado, assim alunos dão início ao período letivo e não concluem. Desta forma o abandono escolar se manifesta como um grande problema social e sua consequência a exclusão social ${ }^{3}$.

A EJA surge diante deste contexto social e exclusivo, como um potencial de transformação, qualificação e reinserção para o mercado de trabalho, não só para jovens e adultos, mastambém acolhendo o público idoso.

Segundo o Instituto Brasileiro de Geografia e Estatística (IBGE), em 2010 a população brasileira era composta de 190.755.199 milhões de pessoas. Com as transformações nos perfis sociais, econômicos e políticos, o número populacional cresceu muito, passando à 208,5 milhões de habitantes e uma taxa de crescimento populacional de $0,82 \%$ entre 2017 e 2018 , conforme a estimativa do IBGE da população dos municípios para 2018.

$\mathrm{Na}$ intenção de proporcionar oportunidades para todos, a Secretaria de Educação do Município de São Gonçalo no ano de 2005, em busca de encontrar soluções viáveis e em curto prazo criou o Programa Único de Funcionamento da Educação de Jovens e Adultos $-2^{\circ}$ Segmento da Rede Pública de Ensino do Município de São Gonçalo (EJA). Com base: “[...] $o$ Poder Público viabilizará e estimulará o acesso e a permanência do trabalhador na Escola, mediante ações integradas e complementares entre si. LDB 9394/96Seção V-Art. 37'. ${ }^{6}$

O objetivo da EJAé proporcionar a oportunidade de conclusão dos estudos. Uma proposta educacional diferenciada do modelo escolar convencional, com foco na Lei de Diretrizes e Bases da Educação (LDB 9.304) de 1996, no artigo 37, que preconiza garantir a continuidade para jovens e adultos, que se encontram fora da idade série, e o acesso a permanência do trabalhador na escola, mediante ações integradas e complementares entre si.

A partir destes fatos, se entende que, jovens e adultos brasileiros, que compõe a EJA necessitam de melhores oportunidades para serem inseridos no mercado de trabalho. Uma realidade experienciada por esse grupo, envolvidos por fatores estressores, que de maneira direta ou indireta, alem de contribuir para o aumento da evasão escolar, afetam a saúde desse grupo.

\section{Materiais e método}

Trata-se de uma pesquisa descritiva com abordagem qualitativa, que tem por intenção, compreender a percepção do público escolar, jovens e 
adultos, em relação aosfatores estressores, envolvidos no processo de evasão escolar. Os participantes da pesquisa serão alunos matriculados na Instituição, de forma voluntária onde os mesmos assinaram o termo de consentimento livre e esclarecido (TCLE).

Como prevê a resolução Conselho Nacional de Saúde (CNS) - 466/12 e 510/16, que dispões sobre a pesquisa envolvendo seres humanos, pelo Comitê de Ética da Faculdade de Medicina da Universidade Federal Fluminense (CEP FM/UFF), com seus devidos nomes não revelados, utilizando-se de nomes fictícios.

Participarão desta pesquisa 25 alunos da Educação de Jovens e Adultos com idade de 20 a 70 anos, alfabetizados ou não, alunos que possuem deficiências leves ou brandas, em virtude da metodologia aplicada, por se tratar de entrevista. Será aplicado um questionário dividido em 3 etapas: a)Um perfil sócio demográfico, b) Percepção do estudante quanto ao abandono escolar (planilha), c) Uma visão panorâmica do auto-cuidado e do acesso a saúde.

A coleta ocorreu nos meses de Novembro e Dezembro de 2019. De maneira que os dados serão analisados a partir da transcrição das falas dos estudantes e análise das entrevistas. Inicialmente os discursos serão numerados e lidos de maneira integral, com a finalidade de apreender o sentido de uma forma ampla e posterior interpretação, com base na leitura de Amadeu George na construção de categorias.

\section{Resultados Esperados}

Os resultados encontrados a partir desse estudo com os alunos da Educação de Jovens e Adultos serão um alicerce para se revelar fatores estressores vivenciados por esse grupo, promovendo assim, uma relação direta com a diminuição da evasão escolar.

A partir desse conhecimento, elaborar estratégia e ações junto ao Projeto Político Pedagógico da Escola como: roda de conversa e reflexões com o corpo discente da EJA, na intenção de superar desafios e melhorar a auto-estema desse grupo. Diante desse contexto, consolidar a Fenomenologia como método de investigação para pesquisas de experiência vivenciada no universo da Educação.

\section{Referências}

1. Feitosa, D. M. Saúde e bem-estar na escola: Reflexões sobre uma experiência com alunos da educação de jovens e adultos. Vita et Sanitas, Trindade-GO, n.08, jan-dez./2014

2. Brasil,Estatuto da criança e do adolescente (1990)]. Estatuto da criança e do adolescente e legislação correlata [recurso eletrônico]: Lei n. 8.069, de 13 de julho de 1990, e legislação correlata. - 12. ed. - Brasília: Câmara dos Deputados, Edições Câmara, 2014. 241 p. - (Série legislação; n. 122) Atualizada em 23/7/2014. ISBN 978-85-402-0237-5 Disponível em: http://www2.camara.leg.br/a-camara/estruturaadm/gestao-na-camara-dosdeputados/responsabilidade-social-e-ambiental/acessibilidade/legislacao- pdf/estatuto-da-crianca-e-do-adolescente. Acesso em 15/06/2018.

3. Silva Filho R. B., Lima Araujo, R. M. L. Evasão e abandono escolar na educação básica no Brasil, Educação Por Escrito, Porto Alegre, v. 8, n. 1 , p. 35-48, jan.-jun. 2017.

4. Hirsch, Carolina Domingues etal. Fatores percebidos pelos acadêmicos de enfermagem como desencadeadores do estresse no ambiente formativo. Texto contexto - Enferm., Florianópolis, v. 27, n. 1, e0370014, 2018.

5. Brasil, Senado Federal. Lei de Diretrizes e Bases da Educação Nacional. No 9394/96. Brasília, 2005. Disponível em: https://www2.senado. leg.br/bdsf/bitstream/handle/id/70320/65.pdf. Acesso em: 5/06/2018.

6. Brasil. Ministério da Saúde. Secretaria de Atenção à Saúde. Núcleo Técnico da Política Nacional de Humanização. Humaniza SUS: documento base para gestores e trabalhadores do SUS. $3^{\mathrm{a}}$ ed. Brasília: Ministério da Saúde; 2008. 